\title{
Importância socioeconômica da mandioca (Manihot esculenta Crantz) para a comunidade de Jaçapetuba, município de Cametá, PA
}

\section{Socioeconomic importance of cassava (Manihot esculenta Crantz) for the community of Jaçapetuba, municipality of Cametá, PA}

\section{Importancia socioeconómica de la yuca (Manihot esculenta Crantz) para la comunidad de Jaçapetuba, municipio de Cametá, PA}

ludis Damasceno Lobo ${ }^{1}$ Cezário Ferreira dos Santos Júnior ${ }^{2}$ Aline Nunes ${ }^{3}$

${ }^{1}$ Graduado em Agronomia pela Universidade Federal do Pará (UFPA). Tem experiência na área de socioeconomia, produção de alimentos e desenvolvimento sustentável. Universidade Federal do Pará (UFPA). E-mail: damascenolobo@gmail.com

${ }^{2}$ Doutorando em Produção Vegetal pela Universidade do Estado de Santa Catarina (UDESC/CAV). Mestre em Agricultura Familiar e Desenvolvimento Sustentável pela Universidade Federal do Pará (UFPA). Especialista em Biocombustível e Extração de Oleaginosas da Amazônia e Graduado em Engenharia Agronômica pela Universidade Federal Rural da Amazônia (UFRA). Tem experiência na área de Pesquisa Socioeconômica Ambiental, com ênfase em recursos naturais, atuando principalmente nos seguintes temas: produção agrícola e extrativista. E-mail: agrosantos01@gmail.com

${ }^{3}$ Mestranda em Produção Vegetal na Universidade do Estado de Santa Catarina (UDESC/CAV). Graduada em Ciências Biológicas no Centro Universitário Unifacvest. Tem experiência em educação ambiental, homeopatia, produção vegetal, plantas medicinais, desenvolvimento sustentável, agroecologia e levantamento de fauna e flora. E-mail: alinenunes_bio@hotmail.com 
Resumo: A mandioca (Manihot esculenta Crantz) é considerada a terceira maior fonte mundial de carboidratos na alimentação humana. Atualmente, o Brasil é o segundo maior produtor de mandioca do mundo. No entanto, faz-se necessário o conhecimento das diferentes relações socioeconômicas envolvendo a cultura da mandioca na Amazônia. Dessa maneira, o estudo objetivou estabelecer como a produção da mandioca se insere nas vidas dos camponeses locais e as transações econômicas envolvidas dentro da comunidade de Jaçapetuba, no município de Cametá, nordeste do estado do Pará. Os resultados demonstram que a renda mensal por derivados da mandioca gera valores superiores às demais atividades agrícolas. No entanto, $70 \%$ da produção de mandioca é passada aos atravessadores, sendo que somente 19\% direcionam-se à feira de Cametá e 11\% permanecem no mercado local. Essas condições demonstram o baixo nível de organização dos camponeses e falta de incentivos à cultura.

Palavras-chave: cadeia produtiva; dificuldades de produção; organização social.

Abstract: Cassava (Manihot esculenta Crantz) is one of the world's largest sources of carbohydrates in human food. Currently, Brazil is the second largest producer of cassava in the world. However, it is necessary to know the same socioeconomic relations with the cassava culture in the Amazon. Thus, the study aimed to establish itself as a production of the local peasants' own population and their activities within the community of Jaçapetuba, in the municipality of Cametá, in the northeastern state of Pará. The results shown are higher than the annual average. However, $70 \%$ of the cassava production is the beach of the middlemen, with only $19 \%$ being directed to the fair of Cametá and $11 \%$ to the local market. These conditions demonstrate the level of organization of peasants and the lack of incentives to culture.

Keywords: productive chain; production difficulties; social organization.

Resumen: La yuca (Manihot esculenta Crantz) es considerada la tercera mayor fuente mundial de carbohidratos en la alimentación humana. Actualmente, Brasil es el segundo mayor productor de mandioca del mundo. Sin embargo, se hace necesario el conocimiento de las mismas relaciones socioeconómicas con la cultura de la mandioca en la Amazonia. De esta forma, el estudio objetivó establecerse como una producción de la propia población de campesinos locales y sus asotividades dentro de la comunidad de Jaçapetuba, en el municipio de Cametá, en el nordeste del estado de Pará. Los resultados demostrados son superiores a la media anual. Sin embargo, el 70\% de la producción de mandioca es la playa de los atravesadores, siendo que sólo el 19\% se dirige a la feria de Cametá y el 11\% para el mercado local. Estas condiciones demuestran el nivel de organización de los campesinos y la falta de incentivos a la cultura.

Palabras clave: cadena productiva; dificultades de producción; organización social. 


\section{INTRODUÇÃO}

A mandioca (Manihot esculenta Crantz) é uma planta do tipo heliófila, arbustiva e pertencente à família Euphorbiaceae. É uma cultura originária do Brasil e está entre os alimentos mais consumidos no mundo por possuir uma importante fonte de carboidrato, o amido. Apresentando grande capacidade adaptativa, mesmo em condições desfavoráveis de solo e clima, é amplamente utilizada no consumo humano, animal e industrial. Sendo uma cultura difundida no país, a mandioca representa papel importante na geração de emprego e renda, principalmente aos pequenos e médios produtores rurais. A vantagem no cultivo da mandioca em relação às demais culturas agrícolas está relacionada ao seu amplo aproveitamento, já que são utilizadas desde as folhas e caules até as raízes para geração de alimento. Na Amazônia, a mandioca tem diversas utilidades na culinária local, das suas raízes são produzidos a farinha seca, farinha d'água, farinha temperada, beiju, tapioca, carimã ou massa puba, tucupi e ingredientes de pratos típicos como tacacá, e das folhas, a maniçoba.

O cultivo da mandioca no Brasil está historicamente associado aos grupos camponeses tradicionais, possuindo grande importância econômica e cultural para a agricultura familiar, fazendo parte da dieta alimentar das populações rurais e urbanas, consumido principalmente na forma de farinha.

De acordo com o Instituto Brasileiro de Geografia e Estatística (IBGE), os produtores familiares são responsáveis por mais da metade de toda a produção nacional da mandioca. E a maior parte da produção da mandioca é destinada à fabricação de farinha, o restante desta para alimentação humana, animal e na obtenção de fécula.

Em regiões produtoras de farinha são utilizadas práticas tradicionais de beneficiamento, onde os agricultores detêm todos os conhecimentos no interior de suas propriedades. Todo o processo é feito de forma artesanal, sendo que a mão de obra é a própria família do produtor.

A produção brasileira de raiz de mandioca atingiu 23,71 milhões de toneladas em 2016, representando 1,55 milhões de hectares colhidos. De acordo com os dados da Companhia Nacional de Abastecimento (CONAB), o estado do Pará é o maior produtor de mandioca do Brasil, com uma safra de 4,19 milhões de toneladas em 2017. O estado apresenta uma crescente 
área colhida, sendo que, em 2016, contava com 350.425 hectares, e 2017 a área foi de 360.662 hectares.

Para as comunidades amazônidas, a cultura da mandioca tem grande importância, pois o seu cultivo e a produção de farinha são realizados por algumas famílias, tornou-se meio para própria subsistência e para geração da principal forma de renda familiar. No entanto alguns entraves são observados no processo socioeconômico nas comunidades amazônidas, entre estas destacam-se os principais problemas enfrentados como, falta de auxílio político, perda de lucro por conta de atravessadores, inexistência de cooperativas nas comunidades e dificuldades no acesso a transporte e educação.

Dessa forma, visando compreender a dinâmica socioeconômica sobre a cultura da mandioca para a comunidade amazônida de Jaçapetuba no município de Cametá, região nordeste do estado do Pará, o artigo retrata os tipos de trabalho realizados, o comércio formal e informal, a utilização dos atravessadores, os níveis de organização social da comunidade, a renda gerada por meio do cultivo da mandioca, bem como, as dificuldades quanto à produção.

\section{MATERIAL E MÉTODOS}

O município de Cametá é composto por aproximadamente 132.515 pessoas, das quais 60\% são de áreas rurais (IBGE, 2016). A pesquisa foi realizada na comunidade de Jaçapetuba, localizada no distrito de Mupi, no município de Cametá, região nordeste paraense sob as coordenadas geográficas $\left(2^{\circ} 8^{\prime} 50.30^{\prime \prime}\right.$ S e $49^{\circ} 28^{\prime} 56.58^{\prime \prime}$ O) (Figura 1). A comunidade conta com aproximadamente 50 famílias, das quais cerca de 40 trabalham especificamente com a cultura de mandioca. 
Figura 1 - Mapa da localização da comunidade de Jaçapetuba, município de Cametá, PA

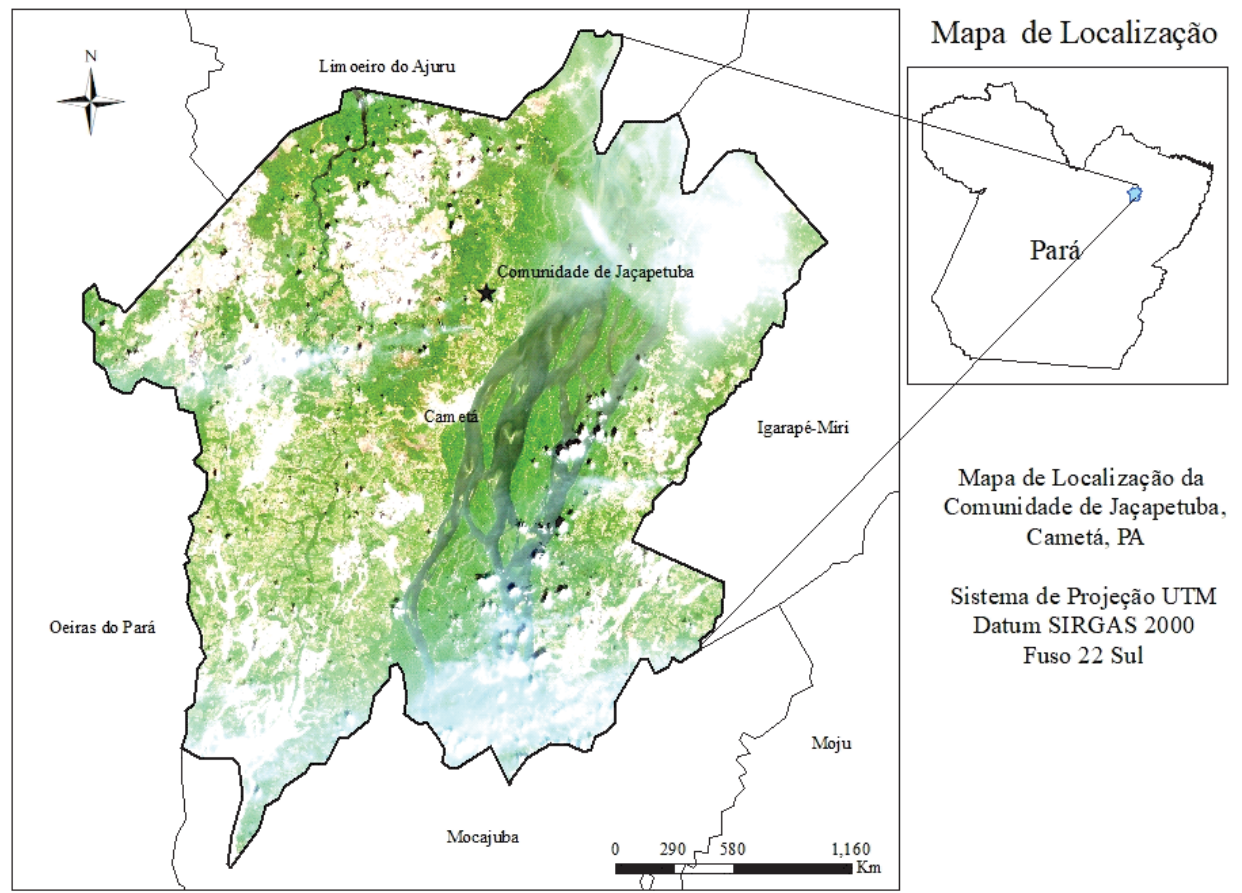

Fonte: Elaborada pelos autores (2018).

Para a elaboração da pesquisa, foram usados os procedimentos metodológicos de abordagem quanti-qualitativo através da coleta de dados com aplicação de questionário, entrevistas e observação em campo com agricultores envolvidos em todo o processo produtivo da cultura de mandioca, desde o plantio até o beneficiamento.

Inicialmente foi realizado um questionário contando com a participação de 27 agricultores, durante quatro meses (setembro a dezembro). No questionário foram realizadas perguntas demográficas, a fim de levantar um histórico do respondente, sendo questionado quanto a sexualidade, idade e número de pessoas que vivem na mesma casa, no entanto, quanto ao nome, optou-se por manter-se anonimamente.

Foram realizadas perguntas em que foram recolhidos dados sobre a renda mensal dos agricultores, a forma de produção, dificuldades encontradas durante o processo e o beneficiamento da mandioca para produção de 
farinha. Posteriormente foram realizadas visitações junto aos agricultores nas áreas de plantio, para observações e registro de mais informações. As respostas foram tabuladas e analisadas utilizando o software Sigmaplot versão 10.0.

\section{RESULTADOS E DISCUSSÃO}

\subsection{Descrição dos agricultores entrevistados}

A aplicação de questionário contou com a participação de $67 \%$ do total de agricultores que trabalham com a cultura da mandioca (cultivo e beneficiamento de farinha) na comunidade de Jaçapetuba. Entre os entrevistados, $78 \%$ eram do sexo masculino, enquanto $22 \%$ eram do sexo feminino. Na agricultura familiar, as atividades agrícolas no campo vêm sendo prioritariamente desenvolvidas por homens, assim como a chefia do lar, restringindo as mulheres às atividades domésticas. Mas nos últimos anos as mulheres vêm ocupando diferentes profissões, o que tem possibilitado melhores condições de renda, passando a ter maior inserção nas decisões da unidade familiar (BRUMER, 2004).

A faixa etária dos agricultores entrevistados variou entre 21 a 45 anos, sendo que 70\% dos agricultores apresentavam entre 36 a 45 anos. Quanto ao estado civil dos agricultores, 22 tinham união estável, quatro eram casados e um era solteiro. Durante a entrevista, questionou-se também quanto aos filhos dos agricultores, sobre os quais se relatou que 11 possuem mais de três filhos, nove destes possuem três, e sete dos entrevistados disseram ter dois filhos. Observa-se que os indivíduos que possuem mais filhos são aqueles com idade superior a 36 anos. Entre os relatos, os mais jovens (21 a 36 anos) abordam a dificuldade em manter uma família maior, portanto, preferem ter menos filhos.

Em relação ao grau de instrução dos agricultores, 78\% revelaram possuir o ensino fundamental, 15\% possuem ensino médio, e $7 \%$ relataram que não são alfabetizados. A baixa escolaridade dos agricultores se deve principalmente ao baixo investimento na educação na localidade, pois existe apenas uma escola, que funciona somente até o ensino fundamental. Se o indivíduo quiser ampliar os estudos, precisa migrar para outras localida- 
des, dificultando assim, o avanço na escolaridade entre os agricultores. Rodrigues, Ignotti e Hacon (2016) relatam que as escolas das comunidades normalmente são multisseriadas, com número de professores reduzidos, enfrentam a crescente evasão escolar devido à distância das escolas e necessidade de os adolescentes auxiliarem no trabalho rural.

Dos agricultores entrevistados, 13 relatam que trabalham há quase 20 anos, seis trabalham há 10 anos, e oito trabalham há mais de 20 anos na agricultura. Esses dados demonstram que as famílias já estão na comunidade por um período considerado alto. Essa manutenção na área se deve principalmente à cultura da mandioca, que possibilita condições favoráveis para a permanência dos agricultores nas unidades produtivas.

Quanto ao tamanho das propriedades, quatro agricultores possuem até 30 hectares, 17 têm entre 10 a 20 hectares e seis até 10 hectares. Isso mostra que não há grande concentração de terras por parte desses agricultores. Entre populações e comunidades tradicionais, existem fortes laços de afinidade entre si, demostrando a existência de "práticas econômicas de reciprocidade", em que os camponeses exploram os recursos no sentido da perpetuação do núcleo familiar, apresentando um menor sentido de acumulação de riqueza (SABOURIN, 2017).

Na produção de mandioca, há predominância da pequena propriedade, portanto é realizada por pequenos produtores. Contudo existe uma produção considerável nas propriedades familiares que é refletida na continuidade desses agentes nas suas unidades produtivas, devido ao fator de o agricultor possuir flexibilidade e diversificação de culturas, assim como, capacidade gerencial de suas terras, diminuindo o processo de êxodo rural (SILVA; CAVALCANTE; SILVA, 2016).

O cultivo de mandioca no país está associado historicamente aos grupos camponeses, e mesmo como pequenos produtores, são responsáveis por grande parte da produção da cultura (FREITAS; FARIAS; VILPOUX, 2011). Essa produção constitui uma estratégia para segurança alimentar das famílias dos produtores e diversificação para a alimentação animal, além de contribuir efetivamente na renda mensal familiar (VIEIRA et al., 2015). 


\subsection{Políticas públicas ligadas à cultura da mandioca}

Averiguou-se que a atuação das políticas públicas e os créditos agrícolas ainda são pouco efetivos na comunidade, dificultando o processo de desenvolvimento da cultura da mandioca. Constatou-se que nenhum dos agricultores possuem o Cadastro Ambiental Rural (CAR), documento obrigatório para aquisição de financiamento, tornando mais difícil o acesso a essas políticas públicas. Conforme o Ministério de Meio Ambiente (MMA) a inscrição no CAR é obrigatória desde 2009 para todos os imóveis rurais, sejam eles públicos ou particulares. Atualmente, o Decreto n. 7.830, de 17 de outubro de 2012 dispõe sobre a necessidade do Sistema de Cadastro Ambiental Rural (SICAR) e o Cadastro Ambiental Rural (CAR). Sendo que pelo mesmo Decreto estabelece as normas aos Programas de Regularização Ambiental exigida aos produtores rurais (BRASIL, 2012).

Os principais motivos que implicam a não regularização das áreas de produção para recebimento de crédito agrícola está no desconhecimento por parte dos agricultores sobre a existência do CAR e falta de orientação técnica dos órgãos competentes, como relata um agricultor da comunidade:

Aqui nós não recebemos nenhum tipo de assistência técnica na nossa roça, tudo é feito com o nosso próprio conhecimento mesmo, já tentei pedir um financiamento no banco, mas era obrigado eu ter esse documento da terra, o CAR né, dai eu fui tirar, mas até agora não veio ninguém aqui tirar (O.G., Agricultor, 42 anos).

Como forma de atenuar esses problemas, seria essencial a atuação mais efetiva da assistência técnica junto aos agricultores, possibilitando, assim, um maior desenvolvimento para a comunidade por meio do incremento de financiamentos. Alguns subsídios são voltados para a agricultura familiar, como é o caso do Programa Nacional de Fortalecimento da Agricultura Familiar (PRONAF), cujo auxílio poderia beneficiar os agricultores para um maior desenvolvimento das culturas da propriedade.

Dos indivíduos entrevistados, detectou-se que cerca de 97\% das famílias são contemplados com o programa Bolsa Família. Além disso, em 30\% das famílias, há alguém aposentado, auxiliando na renda da família. Segundo Santos Júnior et al. (2017) analisaram, as políticas sociais de distribuição de renda como a Bolsa Família e as aposentadorias assumem grande relevância 
econômica para agricultores. Contudo, quando analisadas as categorias de rendas advindas do agroextrativismo (agricultura, pecuária e extrativismo) e venda de mão de obra, estas se mostram como estratégias superiores para os camponeses, além disso, a agricultura para as comunidades tradicionais na Amazônia, muitas vezes, restringe-se somente ao autoconsumo.

\subsection{Dinâmica de trabalho e produção de mandioca na comunidade de Jaçapetuba}

A importância da inclusão da mandioca nas dietas alimentares está na fonte rica em carboidratos que esta possui, apresentando cerca de $30 \%$, onde 25-40\% é amido (ADEOTI, 2010). A mandioca representa ainda um dos produtos no fornecimento de alimentos caracterizado como grande potencial para a segurança alimentar (ZEMBA; KEFAS; HAMZA, 2017).

A mão de obra utilizada no cultivo da mandioca é exclusivamente familiar, em que todos participam de alguma maneira do trabalho, das crianças aos idosos. Ainda ocorrem mutirões nos quais uma família ajuda a outra, principalmente nas fases de preparo da área e plantio, assegurando assim, um laço social fraterno entre as famílias da comunidade.

A parte considerada mais importante da mandioca é o beneficiamento, utilizado na produção de farinha seca, d'água e mista, a fécula ou goma, o tucupi e a farinha de tapioca (BEZERRA, 2006; FRANCK et al., 2011).

A produção e beneficiamento da farinha na comunidade ocorre de forma artesanal nas "Casas de Farinha". As casas de farinha são locais típicos de beneficiamento da mandioca em farinha e outros derivados, pelos agricultores tradicionais da Amazônia. De acordo com a definição do Serviço Brasileiro de Apoio às Micro e Pequenas Empresas (SEBRAE, 2006), essas casas de farinhas geralmente são empreendimentos de pequeno porte, utilizando mão de obra familiar, diferenciando muito das grandes farinheiras que são utilizadas para produção em escala industrial. Segundo Cruz e Schneider (2010), os alimentos produzidos tradicionalmente são considerados pelos consumidores como processo ambiental, social e economicamente sustentáveis, além de fazer parte da cultura da região.

Para a produção de farinha d'água utilizando técnica de beneficiamento artesanal, é necessária uma tonelada de raiz para produzir em média 
cinco sacas de farinha. No Estado do Pará, estudo realizado por Silva, Silva e Rocha (2002) demonstram que, para a realização do processo, são gastos em média 10 horas, envolvendo 12 pessoas, sendo assim, considerada uma atividade bastante desgastante aos produtores. Contudo a produção nas unidades familiares dependerá muito da mão de obra disponível.

Verificou-se que $75 \%$ dos agricultores entrevistados possuem casa de farinha, e nos estabelecimentos há energia elétrica e poço artesiano, facilitando a dinâmica de trabalho nas unidades produtivas, diferente de outras comunidades que carecem de infraestrutura.

De acordo com o Ministério da Agricultura, Pecuária e Abastecimento (MAPA), são fornecidos regulamentos a serem seguidos para a produção de farinha de mandioca. Dessa maneira, a Instrução Normativa 52/2011 estabelece o Regulamento Técnico, em que:

Considera-se farinha de mandioca o produto obtido de raízes de mandioca, do gênero Manihot, submetidas a processo tecnológico adequado de fabricação e beneficiamento; e farinha de mandioca seca o produto obtido das raízes de mandioca sadias, devidamente limpas, descascadas, trituradas, raladas, moídas, prensadas, desmembradas, peneiradas, secas à temperatura adequada, podendo novamente ser peneirada e ainda beneficiada. (BRASIL, 2011).

Na comunidade de Jaçapetuba, após a colheita, é feito o processamento da mandioca, no qual as raízes são transportadas para a casa de farinha. No entanto os agricultores relatam encontrar dificuldades para transportar a matéria prima, pois não existem veículos apropriados para tal processo, sendo que, após a colheita, tem-se no máximo 24 para transportar o produto, já que, depois deste período, as raízes ficam suscetíveis a ataques de microrganismos. Assim, as raízes de mandioca precisam ser recebidas à temperatura ambiente, dispostas em sacos de polietileno limpos, e o veículo de transporte deve ser livre de produtos contaminantes que possam, de alguma forma, comprometer a qualidade da matéria-prima (BEZERRA, 2006).

A partir do momento que chegam até a casa de farinha, as cascas são retiradas (descascadas), as raízes são lavadas e colocadas para ralação ou trituração. Após esse processo, a massa fresca é prensada. A prensagem é realizada a fim de eliminar o excesso de água presente nas raízes após 
o descascamento, e esse processo precisa ser realizado rapidamente para impedir a fermentação e escurecimento da farinha (CHISTÉ; COHEN, 2006).

Santanna e Miranda (2004) descrevem que o processo industrial das raízes de mandioca para fabricação da farinha, passam por oito processos, sendo: a recepção das raízes, descascamento, ralagem, prensagem, peneiragem, torrefação, acondicionamento e armazenagem.

O próximo processo consiste em peneirar, e então a mandioca pode ser torrada (seca) no forno. Os agricultores abordam que, para o processo de torração da farinha no forno, também encontram dificuldades, já que a atividade é bastante desgastante e, uma vez que essa etapa inicia, não pode ser interrompida, pois pode comprometer a qualidade da farinha.

Trabalhar com a mandioca é muito bom, mas dá muito trabalho também viu. Olha, tu tens que fazer várias atividades pra chegar até a farinha. Mas o trabalho mais desgastante para nós com certeza é a torração da farinha aqui no forno, isso porque a partir que a gente começa não pode parar mais né. Nem comer direito a gente come quando tá nesse trabalho (A.M., Agricultor, 39 anos).

De acordo com Sousa e Piraux (2015), estudando sobre a construção social da qualidade da farinha da mandioca em comunidades da Amazônia, o processo da torração é responsável por diminuir a umidade da massa, garantindo dessa maneira a estabilidade microbiológica e consequentemente a qualidade desta. Sobre o processo, ainda dispõem que as comunidades fazem a retirada de raízes pobres, pois facilita a etapa de torração e diminui a quantidade de fiapos e crueira, tornando a farinha de melhor qualidade.

Todas as etapas realizadas são essenciais para a produção de uma farinha de mandioca de qualidade. Os agricultores relatam que, mesmo com as dificuldades, atualmente o maior rendimento dos produtos advêm do cultivo da mandioca, portanto mesmo que o processo seja desgastante, é indispensável para a renda familiar.

No caso da comunidade de Jaçapetuba, todos os agricultores pesquisados possuem algum bem material proveniente da renda da mandioca, isso esclarece o quanto é importante essa cultura para a qualidade de vida dos agricultores. Entre os bens adquiridos, estão: construção da própria casa (21\%), compra de eletrodomésticos e eletrônicos (25\%), aquisição de bicicletas (42\%) e motocicletas (12\%). 


\subsection{Rendimento da produção agroextrativista e agrícola}

Dentre as atividades realizadas pelos agricultores da comunidade de Jaçapetuba, a mandioca provém o melhor rendimento, tendo receita bruta mensal de $\mathrm{R} \$ 1.312,81$ por agricultor, ou seja, superior ao salário mínimo, demostrando grande importância econômica para a comunidade.

Tabela 1 - Principal fonte de renda do agroextrativismo na comunidade de Jaçapetuba, 2017

\begin{tabular}{lcc}
\hline Atividade (R\$) & No de lotes observados & Média mensal (R\$) \\
\hline Pimenta-do-reino & 19 & 142,00 \\
Pimenta de cheiro & 14 & 383,57 \\
Castanha-do-pará & 21 & 203,57 \\
Derivados da Mandioca & 27 & $1.312,81$ \\
\hline
\end{tabular}

* Derivados de mandioca: farinha d'água, farinha de tapioca, tapioca (goma) e crueira. Fonte: Elaborada pelos autores (2018).

Outros cultivos da região, mostram uma importância econômica para complementar a renda familiar, como por exemplo a pimenta do reino (Piper nigrum) que é cultivada por 19 agricultores da comunidade e gerou uma renda mensal de apenas $\mathrm{R} \$ 142,00$ por família. A pimenta de cheiro (Capsicum odoriferum), devido produzir em um curto período e por proporcionar bom rendimento ao produtor, gerou uma renda média mensal de R\$ 383,57. A castanha-do-Pará (Bertholletia excelsa) é uma atividade realizada por 21 agricultores, proveniente do extrativismo e possibilita uma ótima renda aos agricultores, ficando em torno R\$203,57 por família. Além disso, existe a criação de alguns animais dentro das propriedades, como exemplo, pato, galinha e porco, que são utilizados apenas para o consumo familiar. 
Figura 2- Produção mensal dos derivados da mandioca, na comunidade de Jaçapetuba, 2017

\section{Consumo e Venda de derivados da mandioca}

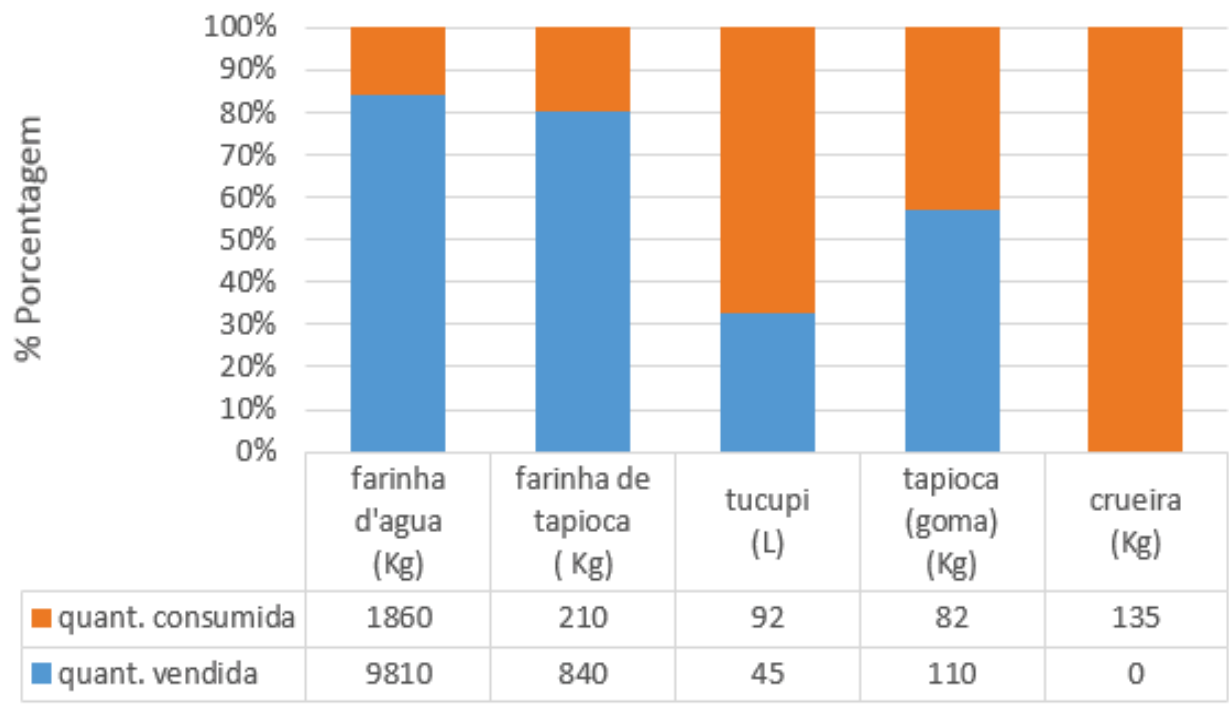

Fonte: Elaborada pelos autores (2018).

Levando em consideração a produção de mandioca (Figura 2), a farinha d'água teve uma produção mensal de $11.670 \mathrm{Kg}$, e destes $9.810 \mathrm{Kg}$ são vendidos e $1.860 \mathrm{Kg}$, consumidos. A produção de farinha de tapioca totaliza $1.050 \mathrm{Kg}$ mensais, $840 \mathrm{Kg}$ vendidos e $210 \mathrm{Kg}$ consumidos. Em relação ao tucupi em goma, 45 litros são vendidos e 92 consumidos, totalizando 137 litros. A tapioca obteve um total de produção de 192 kg, $110 \mathrm{Kg}$ foram vendidos e 82 consumidos. A crueira teve produção de $135 \mathrm{Kg}$ utilizada unicamente para o consumo dos agricultores.

A partir desses dados se constata que a atividade mandioqueira proporciona excelentes vantagens econômicas e sociais aos agentes envolvidos. De acordo com Silva, Alves e Aquino (2011), o cultivo da mandioca tornou-se um elemento histórico brasileiro, o qual cumpre um significativo papel social na segurança alimentar das populações tradicionais. Apresenta uma fonte de renda para as pequenas propriedades familiares e constitui patrimônio vivo de preservação e tradição secular que é transmitida de gerações a gerações. 


\subsection{Processo de venda da cultura de mandioca}

Os agricultores relatam que existe ainda muita dependência de atravessadores para as vendas, pois não há veículo para fornecer o produto diretamente aos consumidores das cidades próximas da comunidade de Jaçapetuba, como Cametá e Limoeiro do Ajuru, distantes $10 \mathrm{~km}$ e $31 \mathrm{~km}$, respectivamente. No entanto os atravessadores controlam a variação do preço, tornando-se um empecilho para os agricultores, pois apesar de produzirem não têm autonomia em relação ao preço final do produto.

Conforme Mayorca e Oliveira (2005), os atravessadores são classificados como agentes de comercialização que atuam como intermediários dentro das cadeias produtivas. Estes criam uma espécie de ponte entre produtores e consumidores, independentemente da origem do produto.

Atualmente, cerca de $70 \%$ da produção de mandioca é passada aos atravessadores, sendo que somente 19\% direcionam-se à feira de Cametá, e $11 \%$ permanecem no mercado local. Para solucionar esse problema, os agricultores visam à criação de uma cooperativa na região, pois poderiam agregar valores a sua produção.

De acordo com a entrevista do agricultor que é liderança sindical da comunidade de Jaçapetuba atualmente, entre os fatores que possibilitariam maior produção e melhor renda no cultivo da mandioca, está justamente a questão dos atravessadores:

Olha seria bom uma cooperativa, porque ia tirar esse atravessador daqui, ia encaixar uma cooperativa aqui ou uma associação, ou uma organização social e também uma máquina era bom porque ia ajudar no preparo da área, e com isso eu teria uma maior produção e maior renda (D.P., Agricultor, 47 anos).

Ao analisar o conceito da palavra cooperação, esta vem do latim operare, que significa fazer algo. No entanto Ferreira (2004, p. 45) dispõe sobre a nomenclatura dada ao cooperativismo como "doutrina econômica que atribui às cooperativas um papel primordial: agregar e associar. Objetiva desempenhar, em beneficio comum, determinada atividade econômica".

De acordo com Kremer, Akahoshi e Cavalheiro (2017), as relações sociais e a cooperação foram ganhando destaque como mecanismo propulsor, pois atuam como transmissores de conhecimentos nas redes. Assim, 
a comunidade se une com intuito de atingir os objetivos, sendo que os envolvidos terão atuação sobre todo o processo e agindo sempre em prol de todos.

Os agricultores de Jaçapetuba seriam amplamente beneficiados caso tivessem auxílio para construir uma cooperativa para aumentar a renda mensal familiar, ao mesmo tempo que promoveria mais ajuda entre os agricultores, havendo troca de produtos entre eles e maior ampliação econômica para a comunidade.

Os produtores carecem de uma atenção especial pelos órgãos competentes de agricultura para solucionar os problemas que afligem e dificultam o processo de desenvolvimento das comunidades, especialmente daquelas que têm bom potencial produtivo, a exemplo, da comunidade de Jaçapetuba que, apesar dessas barreiras, consegue apresentar excelente produção.

\section{CONCLUSÃO}

A cultura da mandioca exerce forte influência na renda dos agricultores das comunidades tradicionais na Amazônia, como o caso de Jaçapetuba no município de Cametá, possibilitando uma renda agrícola mensal (R\$ $1312,81)$ superior às demais atividades, sendo que a farinha d'água é o produto mais procurado e vendido, com produtividade mensal de $11.670 \mathrm{Kg}$, consequentemente, levando a melhores condições de vida dos camponeses. No entanto, para que a produção possa se expandir, existem entraves que devem ser solucionados, tais como, as dificuldades quanto às políticas públicas de crédito, educação e transporte; alta dependência de atravessadores locais que negociam $70 \%$ da produção da mandioca; e necessidade de uma representação social (associativismo e/ou cooperativismo) para melhoria da comercialização na comunidade.

\section{REFERÊNCIAS}

ADEOTI, O. Water use impact of ethanol at a gasoline substitution ratio of $5 \%$ from cassava in Nigeria. Biomass and Bioenergy, v. 34, n. 7, p. 985-92, jul. 2010.

BEZERRA, V. S. Farinhas de mandioca seca e mista Brasília. Brasília, DF: Embrapa Informação Tecnológica, 2006. 
BRASIL. Decreto n. 7.830, de 17 de outubro de 2012. Dispõe sobre o Sistema de Cadastro Ambiental Rural, o Cadastro Ambiental Rural, estabelece normas de caráter geral aos Programas de Regularização Ambiental, de que trata a Lei n. 12.651, de 25 de maio de 2012, e dá outras providências. Diário Oficial da União, Brasília, DF, 17 de outubro de 2011. Disponível em: <http://www2.camara.leg.br/ legin/fed/decret/2012/decreto-7830-17-outubro-2012-774407-publicacaooriginal137903-pe.html>.

. Instrução Normativa Mapa 52/2011, de 8 de novembro de 2011. Estabelecer o Regulamento Técnico da Farinha de Mandioca. Diário Oficial [da] República Federativa do Brasil, Brasília, DF, 8 de novembro de 2011. Disponível em: <http://sistemasweb.agricultura.gov.br/sislegis/action/detalhaAto.do?metho $\mathrm{d}=$ visualizarAtoPortalMapa\&chave=497488882>.

BRUMER, A. Gênero e agricultura: a situação da mulher na agricultura do Rio Grande do Sul. Estudos Feministas, Florianópolis, v. 12, n. 1, p. 205-27, jan./abr. 2004.

CHISTÉ, R. C.; COHEN, K. O. Estudo do processo de fabricação da farinha de mandioca. Belém, PA: Embrapa Amazônia Oriental, 2006.

CRUZ, F. T.; SCHNEIDER, S. Qualidade dos alimentos, escalas de produção e valorização de produtos tradicionais. Revista Brasileira de Agroecologia, v. 5, n. 2, p. 22-38, 2010.

FERREIRA, A. B. H. Novo dicionário Aurélio da Língua Portuguesa. 3. ed. Curitiba: Positivo, 2004.

FREITAS, C. G.; FARIAS, C. S.; VILPOUX, O. F. A produção camponesa de farinha de mandioca na Amazônia sul ocidental. Boletim Goiano de Geografia, Goiânia, v. 31, n. 2, p. 29-42, jul./dez. 2011.

FRANCK, H. et al. Effects of cultivar and harvesting conditions (age, season) on the texture and taste of boiled cassava roots. Food Chemistry, Amsterdan, v. 126, n. 1, p. 127-133, 2011.

INSTITUTO BRASILEIRO DE GEOGRAFIA E ESTATÍSTICA (IBGE). Levantamento sistemático da produção agrícola, Rio de Janeiro, v. 29, n. 12, p. 1-81, dez. 2016.

KREMER, A. M.; AKAHOSHI, W. B.; CAVALHEIRO, R. T. A comunidade de prática sob a ótica da análise de redes sociais: uma aplicação em uma cooperativa brasileira. Revista Perspectiva Online: Humanas e Sociais Aplicadas, v. 7, n. 20, p. 28-42, set./ dez. 2017.

MAYORCA, M. I. O., OLIVEIRA, A. D. S. Os impactos da participação do atravessador na economia do setor agrícola: um estudo de caso. In: CONGRESSO DA SOCIEDADE BRASILEIRA DE ECONOMIA, ADMINISTRAÇÃO E SOCIOLOGIA RURAL- SOBER, 43., Riberão Preto, SP, 2005. Anais... Brasília, DF: SOBER, 2005. v. 1, p. 1-13. 
Importância socioeconômica da mandioca (Manihot esculenta Crantz) para a comunidade de Jaçapetuba, município de Cametá, PA

RODRIGUES, P. C. O.; IGNOTTI, E.; HACON, S. S. Características socioeconômicas, demográficas e de saúde de escolares residentes em duas comunidades da Amazônia meridional brasileira. Revista Ciência e Estudos Acadêmicos de Medicina, Cáceres, MT, v. 6, n. 1, p. 10-23, ago./dez. 2016.

SABOURIN, E. Produção camponesa e seguridade alimentar no Brasil: uma análise pela teoria da reciprocidade. Revista Latinoamericana de Estudios Rurales, Buenos Aires, v. 2, n. 3, p. 1-21, 2017.

SANTANNA, M. E. B.; MIRANDA, M. S. Avaliação microbiológica das etapas de produção da farinha de mandioca no Recôncavo Baiano. Magistra, Cruz das Almas, BA, v. 16, n. 1, p. 25-32, jul./set. 2004.

SANTOS JÚNIOR, C. F.; SÁ, T. D. A.; PORRO, N. S. M.; PORRO, R. Segurança alimentar em assentamentos com ênfase ambiental: um estudo de caso do PDS Virola Jatobá, Transamazônica, Pará, Brasil. Sustentabilidade em Debate, Brasília, v. 8, n. 1, p. 54-66, abr. 2017.

SERVIÇO BRASILEIRO DE APOIO À MICRO E PEQUENAS EMPRESAS (SEBRAE). Manual de referência para casas de farinha. Alagoas, 2006. Disponível em: <http://industriasantacruz.com/wp-content/uploads/2013/09/ ManualdeReferenciaSEBRAE_AL.pdf>.

SILVA, A. C. B.; ALVES, M. A. V.; AQUINO, D. T. A importância da produção da mandioca e a sustentabilidade do espaço na comunidade do Castainho. Breves Contribuciones del I.E.G, Garanhuns, PE, v. 22, n. 22, p. 75-90, 2011.

SILVA, P. L. F.; CAVALCANTE, A. C. P.; SILVA, A. G. Análise da produção agrícola proveniente da agricultura familiar do Município de Pilõezinhos-PB. Élisée, Revista de Geografia UEG, Anápolis, GO, v. 5, n. 1, p. 120-33, jan./jun. 2016.

SILVA, I. T.; SILVA, I. M. O.; ROCHA, B. R. P. Geração de energia a partir de resíduos de mandioca para agricultura familiar no Estado do Pará. In: ENCONTRO DE ENERGIA NO MEIO RURAL, 4. Anais... Campinas, SP, 2002. v. 1.

SOUSA, F. F.; PIRAUX, M. A construção social da qualidade da farinha de mandioca em comunidades rurais na Amazônia paraense. Novos Cadernos NAEA, Belém, PA, v. 18, n. 3, p. 199-222, set./dez. 2015.

VIEIRA, E. A.; FREITAS, J.; CARVALHO, L. J. C. B.; MALAQUIAS, J. V.; FERNANDES, F. D. Desempenho agronômico de acessos de mandioca de mesa em área de Cerrado no município de Unaí, região noroeste de Minas Gerais. Científica, Jaboticabal, SP, v. 43, n. 4, p. 371-7, 2015.

ZEMBA, A. A.; KEFAS, J.; HAMZA, A. Land suitability analysis for decision-making in Cassava (Maihot Spp.) cultivation in southern parto f Adamawa state, Nigéria. Global Journal of Agricultural Sciences, v. 16, n. 1, p. 1-10, 2017. 
